\title{
Associations between Vitamin D Receptor (VDR) Gene Polymorphisms and Colorectal Cancer Risk and Effect Modifications of Dietary Calcium and Vitamin D in a Japanese Population
}

\author{
Nobuyuki Takeshige ${ }^{1,12}$, Guang Yin ${ }^{1}$, Keizo Ohnaka ${ }^{2}$, Suminori Kono ${ }^{1}$, Takashi \\ Ueki $^{3}$, Masao Tanaka ${ }^{3}$, Yoshihiko Maehara ${ }^{4}$, Takeshi Okamura ${ }^{5}$, Koji Ikejiri ${ }^{6}$, \\ Takafumi Maekawa ${ }^{7}$, Yohichi Yasunami ${ }^{8}$, Kenji Takenaka ${ }^{9}$, Hitoshi Ichimiya ${ }^{10}$, \\ Reiji Terasaka ${ }^{11}$
}

\begin{abstract}
Much interest has been drawn to possible associations between vitamin D receptor (VDR) gene polymorphisms and colorectal cancer risk in conjunction with potentially protective effects of calcium and vitamin D. In a study of 685 cases of colorectal cancer and 778 community controls in Japan, we examined the associations of the FokI, BsmI, ApaI, and TaqI polymorphisms with colorectal cancer risk and effect modification by dietary calcium and vitamin D. Genotypes were determined by the PCR-RFLP method. The ApaI polymorphism seemed to be associated with a decreased risk of colorectal cancer, particularly of rectal cancer. The adjusted odds ratio of colorectal cancer for the ApaI AA and Aa genotypes combined versus the aa genotype was $0.83(95 \%$ confidence interval $[\mathrm{CI}]$ 0.67-1.02), and the corresponding value for rectal cancer was 0.75 (95\% CI 0.56-0.99). A decreased risk of colorectal cancer for the ApaI AA and Aa genotypes combined was more evident in individuals with high calcium intake (interaction $\mathbf{p}=\mathbf{0 . 0 5 5}$ ). The FokI polymorphism seemed to be associated with a decreased risk of colon cancer among those with high vitamin $D$ intake (interaction $\mathrm{p}=0.09$ ). The BsmI and TaqI polymorphisms were unrelated to colorectal cancer risk, and the null associations were not modified by calcium or vitamin D intake. In conclusion, the ApaI polymorphism may be associated with a decreased risk of colorectal cancer in Japanese, dependent on dietary calcium intake.
\end{abstract}

Keywords: Colorectal cancer - VDR polymorphisms - calcium - vitamin D - diet - Japan

Asian Pac J Cancer Prev, 16 (5), 2019-2026

\section{Introduction}

Colorectal cancer is the third most common cancer in the world, with more than one million cases occurring every year (Ferlay et al., 2010). In Japan, the incidence rates of colorectal cancer rapidly increased until 1990s and have remained at the world highest levels (Kono 2004; Ferlay et al., 2010). Among the lifestyle factors which convincingly confer increased risk of colorectal cancer are physical inactivity, obesity, alcohol drinking, and high intake of red meat (World Cancer Research Fund and American Institute for Cancer Research 2007). Less convincing is the protective role of calcium intake as well as of dietary fiber. A possible protective role of vitamin D was noted as early as three decades ago (Garland et al., 1985), and supportive evidence has accumulated in the past decades (Gorham et al., 2007; Touvier et al., 2011). In addition to the role in calcium metabolism, the active metabolite of vitamin D itself exerts pleiotropic effects of regulating genes responsible for cell proliferation, differentiation, angiogenesis, and apoptosis (Holick 2007). Vitamin D receptor (VDR) is expressed in colorectal epithelium among other tissues, and may be directly or indirectly involved in colorectal carcinogenesis. Much attention has recently been drawn to potential associations of the VDR gene polymorphisms with colorectal cancer risk (Raimondi et al., 2009; Touvier et al., 2011; Bai et al., 2012; Nassiri et al., 2013).

${ }^{1}$ Department of Preventive Medicine, ${ }^{2}$ Department of Geriatric Medicine, ${ }^{3}$ Department of Surgery and Oncology, ${ }^{4}$ Department of Surgery and Science, Graduate School of Medical Sciences, Kyushu University, ${ }^{5}$ Department of Gastroenterological Surgery, ${ }^{6}$ Division of Surgery, National Kyushu Medical Center, ${ }^{7}$ Department of Surgery, Fukuoka University Chikushi Hospital, ${ }^{8}$ Department of Regenerative Medicine \& Transplantation, Faculty of Medicine, Fukuoka University, ${ }^{9}$ Fukuoka City Hospital, ${ }^{10}$ Hamanomachi General Hospital, ${ }^{11}$ Fukuoka Red Cross Hospital, Fukuoka, Japan, ${ }^{12}$ Department of Neurological Surgery, Kurume University Faculty of Medicine, Kurume, Japan*For correspondence: skono@med.kyushu-u.jp 
The VDR gene is located on chromosome 12q12-q14 and contains more than 60 single-nucleotide polymorphisms (Uitterlinden et al., 2004). Of these, the FokI (rs2228570, formerly rs10735810) and BsmI (rs1544410) polymorphisms have most often been investigated in relation to colorectal cancer (Raimondi et al., 2009; Bai et al., 2012; Yu 2014). The FokI polymorphism changes the location of the start codon and produces a 3 amino-acid longer VDR protein which are less functional (Uitterlinden et al., 2004). The BsmI polymorphism is located at intron 8 near the 3 ' end of the gene. Also known, but less investigated, are the ApaI (rs7975232) at intron 8 and the TaqI (rs731236) at intron 9 (Touvier et al., 2011; Bai et al., 2012). Functional property of these polymorphisms is not known, but they may be linked to the micro satellite repeat in the 3' untranslated region, which affects mRNA stability (Uitterlinden et al., 2004).

Several meta-analyses consistently reported that the BsmI was associated with a decreased risk of colorectal cancer while the FokI was unrelated to colorectal cancer risk (Raimondi et al., 2009; Touvier et al., 2011; Bai et al., 2012; Yu et al., 2014). A notable finding in these meta-analyses is that the associations with the FokI and BsmI polymorphisms varied substantially with studies. A limited number of studies have been reported on these two polymorphisms and colorectal cancer in Mongoloid Asians (Wong et al., 2003; Park et al., 2006; Li et al., 2009). Furthermore, few studies have addressed the effect modification of calcium or vitamin D on the associations between the VDR polymorphisms and colorectal cancer, reporting inconsistent findings (Wong et al., 2003; Slattery et al., 2004; Theodoratou et al., 2008). In the present study, we examined the associations of the above-described four VDR polymorphisms with colorectal cancer risk and the effect modifications of dietary calcium and vitamin $\mathrm{D}$ in the Fukuoka Colorectal Cancer Study (Kono et al, 2004).

\section{Materials and Methods}

The present study used data of the Fukuoka Colorectal Cancer Study, which is a population-based case-control study of residents living in Fukuoka City and three adjacent areas. The study protocol was approved by the ethics committees of the Kyushu University Faculty of Medical Sciences and the participating hospitals. The study design and methods have been described in detail elsewhere (Kono et al., 2004).

\section{Subjects}

Cases comprised a consecutive series of patients with histologically confirmed incident colorectal adenocarcinomas who were admitted to two university hospitals or six affiliated hospitals for surgical treatment during the period October 2000 to December 2003. Eligible cases were aged 20-74 years at time of diagnosis, lived in the study area, and had no prior history of partial or total removal of the colorectum, familial adenomatous polyposis, or inflammatory bowel disease. Of the total 1,053 eligible cases, 840 cases $(80 \%)$ participated in the interview, and 685 gave informed consent for genotyping.
Cases of colon and rectal cancers numbered 384 and 290, respectively; the remaining 11 cases had cancers at both sites.

Eligibility criteria for controls were the same as described for the cases except for two conditions, i.e., no prior diagnosis of colorectal cancer and age 20-74 years at the time of selection. A total of 1,500 persons living in 15 geographical areas were selected as control candidates by a two-stage random sampling, and were invited to participate in the study by mail. Of these, 833 persons participated in the survey, and 778 gave an informed consent for genotyping. The participation rate for the interview was $60 \%$ (833/1382), with 118 persons excluded in the denominator for death, migration from the study area, and other reasons (Kono et al., 2004).

\section{Interview}

Research nurses interviewed cases and controls in person regarding smoking, alcohol use, physical activity, and other factors using a questionnaire. The index dates were the date of onset of symptom or screening for cases and the time of interview for controls. Anthropometric questions inquired about height $(\mathrm{cm})$, current body weight $(\mathrm{kg})$, and body weight 10 years earlier. Body mass index $(\mathrm{kg} / \mathrm{m} 2) 10$ years earlier was used in the analysis because current body mass index was unrelated to risk (Isomura et al., 2006). Habitual alcohol consumption 5 years prior to the index date was ascertained. The amount of alcohol was expressed using the conventional Japanese units; one go $(180 \mathrm{~mL})$ of sake, one large bottle $(633 \mathrm{~mL})$ of beer, and half a go $(90 \mathrm{~mL})$ of shochu were each expressed as one unit; and one drink $(30 \mathrm{~mL})$ of whisky or brandy and one glass $(100 \mathrm{~mL})$ of wine were each converted to half a unit. With regard to smoking, ever-smokers were asked about years of smoking and numbers of cigarettes smoked per day for each decade of life from the second to the last decade. Questions on physical activities elicited type of job (sedentary or standing work, work with walking, labor work, hard labor work, and no job), activities in commuting and housework shopping, and leisure-time activities 5 years before. As described in detail previously (Isomura et al., 2006), leisure-time physical activity (including activities in commuting and housework shopping) was expressed as a sum of metabolic equivalents (MET) multiplied by hours of weekly participation in each activity, i.e., in MET-hours per week.

\section{Dietary assessment}

Consumption frequencies and portion sizes of 148 food/beverage items were ascertained by a computerassisted interview, and quantitative intake estimates were obtained for selected nutrients and food groups (Uchida et al., 2007). Individuals were asked to report their usual consumption over the one year prior to onset of symptoms for cases or interview for controls. In a validation study of 28 control study participants who recorded their diets over a period of 7 days in 4 consecutive seasons, Pearson correlation coefficients of energy-adjusted intakes of calcium and vitamin D assessed by the food frequency questionnaire and diet record were 0.55 and 0.18 , respectively. Nutrient intake per day was adjusted to 
$2000 \mathrm{kcal}$ using the regression residual method (Willett, 1990). The associations of dietary calcium and vitamin D intake with colorectal cancer risk were reported previously (Mizoue et al., 2008).

\section{Genotyping}

DNA was extracted from the buffy coat using a commercial kit (Qiagen, Hilden, Germany). The PCRRFLP method was employed for genotyping. The PCR used $1 \mu \mathrm{L}$ of template DNA with a concentration of approximately $50-150 \mathrm{ng} / \mu \mathrm{l}$, and digested products were electrophoresed on an agarose gel.
The fragment containing the FokI polymorphic site was amplified by using the primers described elsewhere (Slattery et al., 2001). Digestion of the 267-bp PCR product with FokI resulted in two fragments, 197-bp and 70-bp, when the FokI site was present. The allele was designated $\mathrm{F}$ (restriction site absent) or $\mathrm{f}$ (restriction site present), and three genotypes (FF, Ff, and ff) were determined. The 801-bp BsmI polymorphic site fragment was amplified by using the primers specified elsewhere (Slattery et al., 2001). The digestion resulted in two fragments, 477-bp and 336-bp, when the BsmI site was present. The resulting alleles were designated B

Table 1. VDR Polymorphisms and Colorectal Cancer Risk

\begin{tabular}{|c|c|c|c|c|}
\hline Genotype & $\begin{array}{l}\text { Cases } \\
\mathrm{n}(\%)\end{array}$ & $\begin{array}{c}\text { Controls } \\
\mathrm{n}(\%)\end{array}$ & $\begin{array}{c}\text { Crude OR } \\
(95 \% \text { CI) }\end{array}$ & $\begin{array}{c}\text { Adjusted OR } \\
(95 \% \mathrm{CI})^{*}\end{array}$ \\
\hline \multicolumn{5}{|l|}{ FokI } \\
\hline FF & $297(43.4)$ & $310(39.8)$ & 1.00 (referent) & 1.00 (referent) \\
\hline $\mathrm{Ff}$ & $308(45.0)$ & $366(47.0)$ & $0.88(0.71-1.09)$ & $0.88(0.70-1.10)$ \\
\hline $\mathrm{ff}$ & $80(11.7)$ & $102(13.1)$ & $0.82(0.59-1.14)$ & $0.83(0.59-1.17)$ \\
\hline $\mathrm{Ff}+\mathrm{ff}$ & $388(56.6)$ & $468(60.2)$ & $0.87(0.70-1.07)$ & $0.87(0.70-1.08)$ \\
\hline \multicolumn{5}{|l|}{ BsmI } \\
\hline bb & 547 (79.9) & 619 (79.6) & 1.00 (referent) & 1.00 (referent) \\
\hline $\mathrm{Bb}$ & $130(19.0)$ & $149(19.2)$ & $0.99(0.76-1.28)$ & $0.98(0.75-1.29)$ \\
\hline BB & $8(1.2)$ & $10(1.3)$ & $0.91(0.35-2.31)$ & $0.72(0.28-1.86)$ \\
\hline $\mathrm{Bb}+\mathrm{BB}$ & $138(20.1)$ & $159(20.4)$ & $0.98(0.76-1.27)$ & $0.96(0.74-1.26)$ \\
\hline \multicolumn{5}{|l|}{ ApaI } \\
\hline aa & $346(50.5)$ & $367(47.2)$ & 1.00 (referent) & 1.00 (referent) \\
\hline $\mathrm{Aa}$ & 277 (40.4) & 334 (42.9) & $0.88(0.71-1.09)$ & $0.82(0.66-1.03)$ \\
\hline $\mathrm{AA}$ & $62(9.1)$ & $77 \quad(9.9)$ & $0.85(0.59-1.23)$ & $0.84(0.58-1.22)$ \\
\hline $\mathrm{Aa}+\mathrm{AA}$ & $339(49.5)$ & $411(52.8)$ & $0.87(0.71-1.07)$ & $0.83(0.67-1.02)$ \\
\hline \multicolumn{5}{|l|}{ TaqI } \\
\hline $\mathrm{TT}$ & $551(80.4)$ & 619 (79.6) & 1.00 (referent) & 1.00 (referent) \\
\hline $\mathrm{Tt}$ & $126(18.4)$ & $153(19.7)$ & $0.93(0.71-1.20)$ & $0.91(0.70-1.19)$ \\
\hline $\mathrm{tt}$ & $8(1.2)$ & $6 \quad(0.8)$ & $1.50(0.52-4.34)$ & $1.15(0.39-3.40)$ \\
\hline $\mathrm{Tt}+\mathrm{tt}$ & 134 (19.6) & $159(20.4)$ & $0.95(0.73-1.22)$ & $0.92(0.71-1.20)$ \\
\hline
\end{tabular}

OR, odds ratio; CI, confidence interval; *Adjusted for sex, age, residence area, cigarette smoking, alcohol consumption, body mass index 10 years before, type of job, leisure-time physical activity, and parental colorectal cancer.

Table 2. VDR Polymorphisms and Risks of Colon and Rectal Cancers

\begin{tabular}{|c|c|c|c|c|}
\hline \multirow[t]{2}{*}{ Genotype } & \multicolumn{2}{|c|}{ Colon cancer $(n=384)^{*}$} & \multicolumn{2}{|c|}{ Rectal cancer $(\mathrm{n}=290) *$} \\
\hline & $\mathrm{n}(\%)$ & $\mathrm{OR}(95 \% \mathrm{CI})^{\dagger}$ & $\mathrm{n}(\%)$ & OR $(95 \% \mathrm{CI})^{\dagger}$ \\
\hline \multicolumn{5}{|l|}{ FokI } \\
\hline FF & $176(45.8)$ & 1.00 (referent) & $117(40.3)$ & 1.00 (referent) \\
\hline Ff & $159(41.4)$ & $0.77(0.59-1.01)$ & $143(49.3)$ & $1.02(0.76-1.37)$ \\
\hline ff & $49(12.8)$ & $0.89(0.59-1.32)$ & $30(10.3)$ & $0.78(0.48-1.24)$ \\
\hline $\mathrm{Ff}+\mathrm{ff}$ & $208(54.2)$ & $0.79(0.62-1.02)$ & $173(59.7)$ & $0.97(0.73-1.28)$ \\
\hline \multicolumn{5}{|l|}{ BsmI } \\
\hline $\mathrm{bb}$ & $302(78.6)$ & 1.00 (referent) & $237(81.7)$ & 1.00 (referent) \\
\hline $\mathrm{Bb}$ & $76(19.8)$ & $1.06(0.77-1.46)$ & $51(17.6)$ & $0.91(0.63-1.30)$ \\
\hline BB & $6(1.6)$ & $0.88(0.31-2.50)$ & $2(0.7)$ & $0.48(0.10-2.25)$ \\
\hline $\mathrm{Bb}+\mathrm{BB}$ & $82(21.4)$ & $1.05(0.77-1.43)$ & $53(18.3)$ & $0.88(0.61-1.25)$ \\
\hline \multicolumn{5}{|l|}{ ApaI } \\
\hline aa & $188(49.0)$ & 1.00 (referent) & $154(53.1)$ & 1.00 (referent) \\
\hline $\mathrm{Aa}$ & $166(43.2)$ & $0.90(0.69-1.18)$ & $104(35.9)$ & $0.69(0.51-0.94)$ \\
\hline $\mathrm{AA}$ & $30(7.8)$ & $0.75(0.47-1.19)$ & $32(11.0)$ & $0.99(0.62-1.58)$ \\
\hline $\mathrm{Aa}+\mathrm{AA}$ & $196(51.0)$ & $0.87(0.68-1.13)$ & $136(46.9)$ & $0.75(0.56-0.99)$ \\
\hline \multicolumn{5}{|l|}{ TaqI } \\
\hline $\mathrm{TT}$ & $305(79.4)$ & 1.00 (referent) & $238(82.1)$ & 1.00 (referent) \\
\hline $\mathrm{Tt}$ & $73(19.0)$ & $0.97(0.70-1.34)$ & $50(17.2)$ & $0.84(0.58-1.21)$ \\
\hline $\mathrm{tt}$ & $6(1.6)$ & $1.34(0.42-4.27)$ & $2(0.7)$ & $0.81(0.15-4.22)$ \\
\hline $\mathrm{Tt}+\mathrm{tt}$ & $79(20.6)$ & $0.99(0.72-1.35)$ & $52(17.9)$ & $0.84(0.59-1.20)$ \\
\hline
\end{tabular}

OR, odds ratio; CI, confidence interval; *Number of the controls is the same as presented in Table $1 ;{ }^{\dagger}$ Adjusted for sex, age, residence area, cigarette smoking, alcohol consumption, body mass index, type of job, leisure-time physical activity, and parental colorectal cancer 
Table 3. Effect Modifications of Calcium and Vitamin D Intake on the Associations between VDR Polymorphisms and Colorectal Cancer Risk

\begin{tabular}{|c|c|c|c|c|}
\hline \multirow[t]{2}{*}{ Genotype } & \multicolumn{3}{|c|}{ OR $(95 \% \mathrm{CI})^{*}$} & \multirow[t]{2}{*}{ Interaction } \\
\hline & Tertile 1 (low) & Tertile 2 & Tertile 3 (high) & \\
\hline \multicolumn{5}{|l|}{ Calcium } \\
\hline \multicolumn{5}{|l|}{ FokI } \\
\hline $\mathrm{FF}$ & 1.00 (referent) & $0.84(0.56-1.27)$ & $0.69(0.45-1.07)$ & \multirow[t]{2}{*}{$\mathrm{p}=0.84$} \\
\hline $\mathrm{Ff}+\mathrm{ff}$ & $0.80(0.55-1.17)$ & $0.78(0.54-1.14)$ & $0.57(0.38-0.86)$ & \\
\hline \multicolumn{5}{|l|}{ BamI } \\
\hline $\mathrm{bb}$ & 1.00 (referent) & $1.00(0.75-1.34)$ & $0.79(0.58-1.10)$ & \multirow[t]{2}{*}{$\mathrm{p}=0.27$} \\
\hline $\mathrm{Bb}+\mathrm{BB}$ & $1.33(0.84-2.11)$ & $0.89(0.55-1.42)$ & $0.63(0.39-1.02)$ & \\
\hline \multicolumn{5}{|l|}{ ApaI } \\
\hline aa & 1.00 (referent) & $0.92(0.63-1.33)$ & $0.95(0.64-1.42)$ & \multirow[t]{2}{*}{$\mathrm{p}=0.05$} \\
\hline $\mathrm{Aa}+\mathrm{AA}$ & $0.98(0.68-1.42)$ & $0.91(0.63-1.31)$ & $0.53(0.36-0.79)$ & \\
\hline \multicolumn{5}{|l|}{ TaqI } \\
\hline $\mathrm{TT}$ & 1.00 (referent) & $1.01(0.76-1.36)$ & $0.80(0.58-1.11)$ & \multirow[t]{2}{*}{$\mathrm{p}=0.18$} \\
\hline $\mathrm{Tt}+\mathrm{tt}$ & $1.33(0.84-2.12)$ & $0.83(0.51-1.32)$ & $0.60(0.37-0.98)$ & \\
\hline \multicolumn{5}{|l|}{ Vitamin D } \\
\hline \multicolumn{5}{|l|}{ FokI } \\
\hline $\mathrm{FF}$ & 1.00 (referent) & $0.88(0.59-1.31)$ & $0.88(0.58-1.34)$ & \multirow[t]{2}{*}{$\mathrm{p}=0.09$} \\
\hline $\mathrm{Ff}+\mathrm{ff}$ & $0.94(0.64-1.1 .37)$ & $0.93(0.64-1.36)$ & $0.53(0.35-0.78)$ & \\
\hline \multicolumn{5}{|l|}{ BamI } \\
\hline $\mathrm{bb}$ & 1.00 (referent) & $0.93(0.69-1.24)$ & $0.70(0.51-0.95)$ & \multirow[t]{2}{*}{$\mathrm{p}=0.86$} \\
\hline $\mathrm{Bb}+\mathrm{BB}$ & $0.96(0.60-1.55)$ & $0.99(0.64-1.54)$ & $0.62(0.38-1.01)$ & \\
\hline \multicolumn{5}{|l|}{ ApaI } \\
\hline aa & 1.00 (referent) & $0.96(0.66-1.39)$ & $0.84(0.57-1.25)$ & \multirow[t]{2}{*}{$\mathrm{p}=0.24$} \\
\hline $\mathrm{Aa}+\mathrm{AA}$ & $0.95(0.65-1.37)$ & $0.88(0.61-1.28)$ & $0.53(0.36-0.78)$ & \\
\hline \multicolumn{5}{|l|}{ TaqI } \\
\hline $\mathrm{TT}^{1}$ & 1.00 (referent) & $0.92(0.69-1.23)$ & $0.69(0.51-0.94)$ & \multirow[t]{2}{*}{$\mathrm{p}=0.84$} \\
\hline $\mathrm{Tt}+\mathrm{tt}$ & $0.89(0.55-1.44)$ & $0.95(0.61-1.50)$ & $0.60(0.37-0.97)$ & \\
\hline
\end{tabular}

OR, odds ratio; CI, confidence interval; Numbers of the subjects were 663 cases and 760 controls; *Adjusted for sex, age, residence area, cigarette smoking, alcohol consumption, body mass index, type of job, leisure-time physical activity, and parental colorectal cancer; ${ }^{\circ}$ Likelihood ratio test comparing two models with and without interaction terms

(restriction site absent) or $\mathrm{b}$ (restriction site present), and three genotypes (BB, Bb, and bb) were determined. The amplification of a fragment containing the ApaI and TaqI polymorphic sites was carried out by means of a single PCR using the primers described previously (Habuchi et al., 2000). Digestion with ApaI revealed genotypes denoted AA (501 bp), Aa (501, 284, and $217 \mathrm{bp}$ ), or aa (284 and $217 \mathrm{bp}$ ), and digestion with TaqI revealed genotypes denoted TT (494 bp), Tt (494, 293, and 201 bp), or tt (293 and $201 \mathrm{bp}$ ).

\section{Statistical analysis}

Comparison of means, medians, and proportions between cases and controls were carried out by t-test, Wilcoxon rank sum test, and chi-square test, respectively. The associations of the VDR polymorphisms or nutrients with colorectal cancer were assessed by using odds ratio (OR) and 95\% confidence interval (CI), which were obtained from logistic regression analysis. The 95\%CI was derived from the standard error of the logistic regression coefficient. Statistical adjustment was made for sex, 5-year age class (starting with the lowest class of $<45$ years), residence area (Fukuoka City or the adjacent areas), body mass index 10 years ago $(<22.5,22.5-24.9$, $25.0-27.4$, or $\left.\geq 27.5 \mathrm{~kg} / \mathrm{m}^{2}\right)$, smoking $(0,1-399,400-799$, or $\geq 800$ cigarettes-years), alcohol intake (0, 0.1-0.9, 1.0-1.9, or $\geq 2.0$ units/day), type of job (sitting or standing work including no job, work with walking, or labor work), leisure-time physical activity $(0,1-15.9$, or $\geq 16$ MET- hours/week), and parental history of colorectal cancer.

In the analysis on the gene-nutrient interaction, the subjects were classified into three categories with respect to calcium or vitamin D intake using the tertiles among the controls. The trend in the OR associated with calcium or vitamin D was assessed by the Wald statistic with ordinal values assigned to the three categories. The effect modifications of calcium or vitamin D intake on the associations with the polymorphisms were assessed by the likelihood ratio test, comparing a model including interaction terms with one that only included the main effects.

Deviation from the Hardy-Weinberg equilibrium was evaluated by chi-square test with one degree of freedom. Statistical significance was declared if a two-sided P-value was less than 0.05. Statistical analyses were carried out using SAS version 9.2 (SAS Institute, Cary, NC), except for the Hardy-Weinberg equilibrium which was assessed by using Stata version 10 (StataCorp, College Station, TX).

\section{Results}

Demographic and lifestyle characteristics of the study subjects have been described previously (Morita et al., 2009; Morita et al., 2013). Females numbered 259 $(37.8 \%)$ in the cases and $288(37.0 \%)$ in the controls $(\mathrm{p}=0.75)$. Mean ages were 60.2 years (SD 9.1 years) among the cases and 58.6 years (SD 10.7 years) among 
Table 4. Effect Modifications of Calcium and Vitamin D Intake on the Associations between VDR Polymorphisms and Colon Cancer Risk

\begin{tabular}{|c|c|c|c|c|}
\hline \multirow[t]{2}{*}{ Genotype } & \multicolumn{3}{|c|}{ OR $(95 \%$ CI $) *$} & \multirow[t]{2}{*}{ Interaction } \\
\hline & Tertile 1 (low) & Tertile 2 & Tertile 3 (high) & \\
\hline \multicolumn{5}{|c|}{ Calcium } \\
\hline \multicolumn{5}{|l|}{ FokI } \\
\hline $\mathrm{FF}$ & 1.00 (referent) & $0.93(0.58-1.49)$ & $0.60(0.36-0.99)$ & $\mathrm{P}=0.53$ \\
\hline $\mathrm{Ff}+\mathrm{ff}$ & $0.72(0.46-1.12)$ & $0.66(0.42-1.03)$ & $0.58(0.36-0.94)$ & \\
\hline \multicolumn{5}{|l|}{ BamI } \\
\hline $\mathrm{bb}$ & 1.00 (referent) & $1.00(0.70-1.43)$ & $0.81(0.55-1.20)$ & $\mathrm{P}=0.34$ \\
\hline $\mathrm{Bb}+\mathrm{BB}$ & $1.46(0.85-2.52)$ & $1.02(0.59-1.77)$ & $0.67(0.37-1.19)$ & \\
\hline \multicolumn{5}{|l|}{ Apa I } \\
\hline aa & 1.00 (referent) & $0.95(0.61-1.50)$ & $0.99(0.61-1.60)$ & $\mathrm{P}=0.12$ \\
\hline $\mathrm{Aa}+\mathrm{AA}$ & $1.08(0.69-1.69)$ & $0.98(0.63-1.53)$ & $0.58(0.36-0.94)$ & \\
\hline \multicolumn{5}{|l|}{ TaqI } \\
\hline $\mathrm{TT}$ & 1.00 (referent) & $1.02(0.71-1.45)$ & $0.83(0.57-1.23)$ & $\mathrm{P}=0.20$ \\
\hline \multirow[t]{2}{*}{$\mathrm{Tt}+\mathrm{tt}$} & $1.49(0.86-2.56)$ & $0.98(0.56-1.71)$ & $0.61(0.34-1.10)$ & \\
\hline & & Vitamin D & & \\
\hline \multicolumn{5}{|l|}{ FokI } \\
\hline $\mathrm{FF}$ & 1.00 (referent) & $0.80(0.50-1.28)$ & $0.76(0.47-1.24)$ & $\mathrm{P}=0.09$ \\
\hline $\mathrm{Ff}+\mathrm{ff}$ & $0.80(0.51-1.26)$ & $0.86(0.55-1.32)$ & $0.40(0.24-0.64)$ & \\
\hline \multicolumn{5}{|l|}{ BamI } \\
\hline $\mathrm{bb}$ & 1.00 (referent) & $0.92(0.65-1.31)$ & $0.65(0.44-0.94)$ & $\mathrm{P}=0.51$ \\
\hline $\mathrm{Bb}+\mathrm{BB}$ & $1.13(0.65-1.96)$ & $1.14(0.68-1.91)$ & $0.51(0.27-0.94)$ & \\
\hline \multicolumn{5}{|l|}{ ApaI } \\
\hline aa & 1.00 (referent) & $0.92(0.59-1.46)$ & $0.82(0.51-1.32)$ & $\mathrm{P}=0.09$ \\
\hline $\mathrm{Aa}+\mathrm{AA}$ & $1.04(0.66-1.62)$ & $0.99(0.64-1.54)$ & $0.46(0.28-0.74)$ & \\
\hline \multicolumn{5}{|l|}{ TaqI } \\
\hline TT & 1.00 (referent) & $0.92(0.65-1.31)$ & $0.64(0.44-0.94)$ & $\mathrm{P}=0.54$ \\
\hline $\mathrm{Tt}+\mathrm{tt}$ & $1.08(0.62-1.88)$ & $1.09(0.65-1.85)$ & $0.49(0.27-0.91)$ & \\
\hline
\end{tabular}

OR, odds ratio; CI, confidence interval; Numbers of the subjects were 374 cases and 760 controls; *Adjusted for sex, age, residence area, cigarette smoking, alcohol consumption, body mass index, type of job, leisure-time physical activity, and parental colorectal cancer; ${ }^{\dagger}$ Likelihood ratio test comparing two models with and without interaction terms

the controls $(\mathrm{p}=0.003)$. The cases had a lower intake of dietary calcium than the controls (median: 608 versus 624 $\mathrm{mg} /$ day, $\mathrm{p}=0.22$ ). Vitamin D intake was also slightly lower in the cases than in the controls (median: 8.25 versus 8.44 $\mu \mathrm{g} / \mathrm{day}, \mathrm{p}=0.24)$.

The associations of the VDR polymorphisms with colorectal cancer risk are shown in Table 1 . The minor allele frequencies of the FokI, BsmI, ApaI, and TaqI polymorphisms were $0.366,0.109,0.314$, and 0.106 , respectively. Genotype frequency was in the HardyWeinburg equilibrium for each polymorphism in the controls (FokI: $\mathrm{p}=0.71$; BsmI: $\mathrm{p}=0.76$; ApaI: $\mathrm{p}=0.94$; and TaqI: $\mathrm{p}=0.30$ ). None of the four polymorphisms was significantly associated with colorectal cancer risk. However, the risk of colorectal cancer was seemingly decreased among individuals with the ApaI minor allele $(\mathrm{p}=0.08)$.

When the analysis was done separately for colon and rectal cancer (Table 2), a modest decrease in the risk of colon cancer, not of rectal cancer, was noted for the FokI Ff and ff genotypes combined ( $\mathrm{p}=0.07)$. A decreased risk of rectal cancer associated with the ApaI Aa and AA genotypes combined was statistically significant $(\mathrm{p}=0.04)$.

Table 3 summarizes the effect modification of calcium and vitamin $\mathrm{D}$ each on the association between each polymorphism and colorectal cancer risk. In this analysis, individuals with one or two minor alleles were combined for stability of the estimates. Adjusted OR $(95 \% \mathrm{CI})$ of colorectal cancer for the first, second, and third tertile categories of dietary calcium intake were 1.00 (referent), 0.92 (0.71-1.20), and 0.71 (0.53-0.95), respectively (trend $\mathrm{p}=0.02$ ), and those for vitamin $\mathrm{D}$ intake were 1.00 (referent), 0.95 (0.73-1.23), and 0.69 $(0.52-0.91)$, respectively (trend $\mathrm{p}=0.01)$. In the low and intermediate categories of calcium and vitamin $\mathrm{D}$ intake, the OR did not much differ from unity. In the high intake of calcium, the ApaI polymorphism was associated with an evident decrease in the risk of colorectal cancer, showing a nearly significant interaction $(\mathrm{p}=0.055)$. A decreased risk associated with the ApaI polymorphism was also slightly more evident in the high category of vitamin D intake although the interaction was far from statistical significance. There was a suggestive, differential decrease in the risk associated with the FokI polymorphism according to vitamin D intake.

The effect modifications of dietary calcium and vitamin D were separately evaluated for colon cancer (Table 4) and rectal cancer (Table 5). Calcium intake tended to be associated with decreased risks of both colon cancer (trend $\mathrm{p}=0.06$ ) and rectal cancer (trend $\mathrm{p}=0.10$ ), and vitamin $\mathrm{D}$ intake was more strongly associated with decreased risks of colon cancer (trend $\mathrm{p}=0.004$ ) and rectal cancer (trend $\mathrm{p}=0.06$ ). None of the interactions tested was statistically significant for either colon or rectal cancer. However, a decreased risk of colon cancer associated with the ApaI polymorphism was noted among individuals with the high intake of calcium or vitamin D. A similar tendency toward such an effect modification was suggested for rectal cancer 
Table 5. Effect Modifications of Calcium and Vitamin D Intake on the Associations between VDR Polymorphisms and Rectal Cancer Risk

\begin{tabular}{|c|c|c|c|c|}
\hline \multirow[t]{2}{*}{ Genotype } & \multicolumn{3}{|c|}{ OR $(95 \% \mathrm{CI}) *$} & \multirow[t]{2}{*}{ Interaction $^{\dagger}$} \\
\hline & Tertile 1 (low) & Tertile 2 & Tertile 3 (high) & \\
\hline \multicolumn{5}{|c|}{ Calcium } \\
\hline \multicolumn{5}{|l|}{ FokI } \\
\hline $\mathrm{FF}$ & 1.00 (referent) & $0.75(0.43-1.32)$ & $0.86(0.49-1.51)$ & \multirow[t]{2}{*}{$\mathrm{P}=0.15$} \\
\hline $\mathrm{Ff}+\mathrm{ff}$ & $0.91(0.56-1.48)$ & $0.99(0.60-1.61)$ & $0.55(0.31-0.96)$ & \\
\hline \multicolumn{5}{|l|}{ BamI } \\
\hline $\mathrm{bb}$ & 1.00 (referent) & $1.06(0.72-1.55)$ & $0.83(0.54-1.27)$ & \multirow[t]{2}{*}{$\mathrm{P}=0.25$} \\
\hline $\mathrm{Bb}+\mathrm{BB}$ & $1.35(0.75-2.45)$ & $0.78(0.40-1.50)$ & $0.57(0.29-1.12)$ & \\
\hline \multicolumn{5}{|l|}{ ApaI } \\
\hline aa & 1.00 (referent) & $0.88(0.55-1.43)$ & $0.94(0.56-1.57)$ & \multirow[t]{2}{*}{$\mathrm{P}=0.15$} \\
\hline $\mathrm{Aa}+\mathrm{AA}$ & $0.83(0.51-1.33)$ & $0.84(0.52-1.36)$ & $0.45(0.27-0.78)$ & \\
\hline \multicolumn{5}{|l|}{ TaqI } \\
\hline $\mathrm{TT}$ & 1.00 (referent) & $1.07(0.73-1.57)$ & $0.82(0.53-1.26)$ & \multirow[t]{2}{*}{$\mathrm{P}=0.25$} \\
\hline \multirow[t]{2}{*}{$\mathrm{Tt}+\mathrm{tt}$} & $1.29(0.70-2.35)$ & $0.69(0.36-1.35)$ & $0.57(0.29-1.11)$ & \\
\hline & \multirow{2}{*}{\multicolumn{4}{|c|}{ Vitamin D }} \\
\hline FokI & & & & \multirow{3}{*}{$\mathrm{P}=0.32$} \\
\hline $\mathrm{FF}$ & 1.00 (referent) & $1.04(0.60-1.78)$ & $0.97(0.55-1.72)$ & \\
\hline $\mathrm{Ff}+\mathrm{ff}$ & $1.24(0.75-2.05)$ & $0.97(0.58-1.62)$ & $0.68(0.40-1.17)$ & \\
\hline \multicolumn{5}{|l|}{ BamI } \\
\hline $\mathrm{bb}$ & 1.00 (referent) & $0.84(0.57-1.23)$ & $0.68(0.45-1.03)$ & \multirow[t]{2}{*}{$\mathrm{P}=0.84$} \\
\hline $\mathrm{Bb}+\mathrm{BB}$ & $0.78(0.40-1.52)$ & $0.85(0.47-1.53)$ & $0.61(0.32-1.16)$ & \\
\hline \multicolumn{5}{|l|}{ ApaI } \\
\hline aa & 1.00 (referent) & $0.91(0.57-1.47)$ & $0.79(0.47-1.32)$ & \multirow[t]{2}{*}{$\mathrm{P}=0.78$} \\
\hline $\mathrm{Aa}+\mathrm{AA}$ & $0.83(0.51-1.35)$ & $0.69(0.42-1.13)$ & $0.51(0.30-0.85)$ & \\
\hline \multicolumn{5}{|l|}{ TaqI } \\
\hline TT & 1.00 (referent) & $0.83(0.57-1.21)$ & $0.67(0.45-1.01)$ & \multirow[t]{2}{*}{$\mathrm{P}=0.73$} \\
\hline $\mathrm{Tt}+\mathrm{tt}$ & $0.68(0.34-1.35)$ & $0.81(0.45-1.48)$ & $0.59(0.31-1.12)$ & \\
\hline
\end{tabular}

$\overline{\mathrm{OR}}$, odds ratio; CI, confidence interval; Numbers of the subjects were 278 cases and 760 controls; *Adjusted for sex, age, residence area, cigarette smoking, alcohol consumption, body mass index, type of job, leisure-time physical activity, and parental colorectal cancer; 'Likelihood ratio test comparing two models with and without interaction terms

as well. A suggestive interaction between FokI and vitamin D was noted for colon cancer, but not for rectal cancer.

\section{Discussion}

The present study indicated that the ApaI polymorphism was associated with a decreased risk of colorectal cancer, particularly of rectal cancer. Calcium appeared to modify the association between ApaI polymorphism and colorectal cancer. The FokI polymorphism seemed to be associated with a decreased risk of colon cancer, especially among individuals with high intake of vitamin D. Neither BmsI nor TaqI polymorphism was associated with the risk of colorectal, colon, or rectal cancer. Nor was an effect modification of either calcium or vitamin D intake observed on the associations with these polymorphisms.

The BmsI BB genotype is considered to confer a modest decrease in the risk of colorectal cancer at least among Caucasians (Raimondi et al., 2009; Touvier et al., 2010; Bai et al., 2012; Yu 2014). It would be difficult to observe such a modest decrease in the Japanese population, in which the BmsI BB genotype is rare as observed in the present study. It was recently reported that BmsI BB and $\mathrm{Bb}$ genotypes were each associated with a substantial decrease in the risk of colorectal cancer in a meta-analysis of three Asian studies (Yu et al., 2014). The three studies were case-control studies in Korea (Park et al., 2006), China (Li et al., 2009), and Iran (Mahmoudi et al., 2011). The Korean and Iranian studies found no association with the BsmI polymorphism at all, while the Chinese study showed an OR of 0.02 for the BB genotype and an OR 0.10 for the $\mathrm{Bb}$ genotype as compared with the bb genotype (Li et al., 2009). In the Chinese study, however, the distribution of BsmI genotypes in the controls was rather aberrant; the proportions of the $\mathrm{bb}, \mathrm{Bb}$, and $\mathrm{BB}$ genotypes were $11.0 \%, 30.0 \%$, and $59.0 \%$, respectively, while the corresponding values in the cases were $73.5 \%, 20.5 \%$ and $6.0 \%$, respectively. The results from the Chinese study ( $\mathrm{Li}$ et al., 2009) should be interpreted with caution.

The ApaI polymorphism has been unrelated to colorectal cancer in the meta-analyses mostly of Caucasian studies (Touvier et al., 2011; Bai et al.,2012). In a Korean study of 190 colorectal cancer cases and 318 healthy controls (Park et al., 2006), the crude OR for the ApaI Aa aand AA genotypes combined was 1.48 (95\% CI 1.03-2.13), as compared with the ApaI aa genotype. The present finding on the ApaI polymorphism is apparently contradictory to the previous observation, but deserves further investigation. The FoxI polymorphism has generally been unrelated to colorectal cancer risk (Touvier et al., 2011; Bai et al.,2012), whereas an earlier study reported an increased risk of colorectal cancer associated with this polymorphism (Wong et al., 2003). The present finding that the FoxI polymorphism was associated with a modest decrease in the risk of colon cancer is compatible with the observation in the Korean study, in which the decrease was more substantial (Park et al., 2006). A recent study showed no material association between the FoxI 
polymorphism and colorectal cancer in Kashmir (Rasool et al., 2013). Again, more studies are needed. The lack of association for the TaqI polymorphism is consistent with previous reports (Touvier et al., 2011; Bai et al.,2012; Atoum and Tchoporyan, 2014).

A limited number of studies addressed the interaction between the VDR polymorphisms and colorectal cancer with stratification by calcium or vitamin D intake. A study in the United States suggested that the BsmI BB genotype was associated with a decreased risk of rectal cancer, not of colon cancer, when calcium intake was low (Slattery et al., 2004). On the other hand, the FokI polymorphism was associated with an increased risk of colorectal cancer when calcium intake was low in Singapore Chinese (Wong et al., 2003). This observation regarding the FokI was not replicated in Scotland (Theodoratou et al., 2008); the risk was nonsignificantly lower for FokI ff genotype, but not for the Ff genotype, as compared with the FF genotype when calcium or vitamin D intake was low. The present study suggested an interaction between calcium intake and the ApaI polymorphism, but the Scottish study did not observe such an interaction on colorectal cancer risk (Theodoratou et al., 2008). Results from few studies of colorectal adenomas are also inconsistent regarding Taq I and serum 25-hydroxyvitamin D (Peters et al., 2004; Yamaji et al., 2012). Results on the gene-nutrient interaction are necessarily more liable to fluctuation, and further studies are needed to clarify the interaction between the VDR polymorphisms and calcium or vitamin D on colorectal cancer risk.

It is well known that the VDR gene polymorphisms show a wide ethnic variation (Zmuda et al., 2000; Uitterlinden et al., 2004). While the FokI variant allele (f allele) is more frequent in Asians than in Caucasians, the BsmI variant allele (B allele) is much less frequent in Asians than in Caucasians. The observed frequencies of the variant alleles of the FokI, BsmI, ApaI, and TaqI polymorphisms are in agreement with those reported elsewhere in Japan (Habuchi et al., 2000; Yamaji et al., 2012). One study reported that frequencies of the BsmI B,ApaI A, and TaqI t alleles were $0.179,0.324$ and 0.118 , respectively (Habuchi et al., 2000), and the other described the frequencies of FokI $f$ and TaqI $t$ alleles as 0.365 and 0.123 , respectively (Yamaji et al., 2012).

Use of community controls, ethnic homogeneity, and evaluation of the gene-nutrient interaction are among strengths of the present study. A relatively low validity of the estimated dietary vitamin D is a weakness in the present study, although the present study found an inverse association between vitamin D intake and colorectal intake. Vitamin D status depends on the degree of sun exposure, and circulating levels of vitamin $\mathrm{D}$ is a better parameter of vitamin D status. While the study size was fairly large, the number of the subjects was not large enough to investigate the effects of homozygous genotype of the infrequent variant alleles such as the BsmI BB and Taq ff genotypes.

In summary, a case-control study in Japan suggested a possible decrease in the risk of colorectal cancer associated with the ApaI polymorphism in the VDR gene, dependent on dietary calcium intake.

\section{Acknowledgements}

Nobuyuki Takeshige was a visiting $\mathrm{PhD}$ student from Kurume University. The authors acknowledge support from Emeritus Professor Keizo Sugimachi; Professors Seiyo Ikeda, Takayuki Shirakusa, and Sumitaka Arima; and Drs. Motonori Saku, Yoichi Ikeda, Soichiro Maekawa, Kazuo Tanoue, Kinjiro Sumiyoshi, and Shoichiro Saito in conducting the survey of cases. The following physicians kindly supervised the survey of controls at their clinics: Drs. Hideaki Baba, Tomonori Endo, Hiroshi Hara, Yoichiro Hirokata, Motohisa Ikeda, Masayoshi Ishibashi, Fumiaki Itoh, Yasuhiro Iwanaga, Hideki Kaku, Shoshi Kaku, Minoru Kanazawa, Akira Kobayashi, Ryunosuke Kumashiro, Shinichi Matsumoto, Soukei Mioka, Umeji Miyakoda, Osamu Nakagaki, Nobuyoshi Nogawa, Nobuyuki Ogami, Toyoaki Okabayashi, Hironao Okabe, Nishiki Saku, Masafumi Tanaka, Masahiro Ueda, Bunichi Ushio, and Koheisho Yasunaga. The authors are grateful to Ms. Hiroko Mizuta, Ms. Masumi Koga and Ms. Kumiko Arie for their technical assistance. The Fukuoka Colorectal Cancer Study was supported by a Grant-in-Aid for Cancer Research on Priority Areas (20014018) and a Grant-in-Aid for Scientific Research on Innovative Areas (221S0001) from the Ministry of Education, Culture, Sports, Science and Technology, Japan. The computation using the SAS software was done at Kyushu University Computer Center.

\section{References}

Atoum MF, Tchoporyan MN (2014). Association between circulating vitamin $\mathrm{D}$, the Taq1 vitamin $\mathrm{D}$ receptor gene polymorphism and colorectal cancer risk among Jordanians. Asian Pac J Cancer Prev, 15, 7337-41.

Bai YH, Lu H, Hong D, et al (2012). Vitamin D receptor gene polymorphisms and colorectal cancer risk: A systematic meta-analysis. World J Gastroenterol, 18, 1672-9.

Ferlay J, Shin HR, Bray F, et al (2010). Estimates of worldwide burden of cancer in 2008: GLOBOCAN 2008. Int J Cancer, 127, 2893-917.

Garland C, Shekelle RB, Barrett-Connor E, et al (1985). Dietary vitamin D and calcium and risk of colorectal cancer: A 19year prospective study in men. Lancet, 1, 307-9.

Gorham ED, Garland CF, Garland FC, et al (2007). Optimal vitamin D status for colorectal cancer prevention: A quantitative meta analysis. Am J Prev Med, 32, 210-6.

Habuchi T, Suzuki T, Sasaki R, et al (2000) Association of vitamin $\mathrm{D}$ receptor gene polymorphism with prostate cancer and benign prostatic hyperplasia in a Japanese population. Cancer Res, 60, 305-8.

Holick MF (2007). Vitamin D deciciency. N Engl J Med, 357, 266-81.

Isomura K, Kono S, Moore MA, et al (2006). Physical activity and colorectal cancer: The Fukuoka Colorectal Cancer Study. Cancer Sci, 97, 1099-104.

Kono S (2004). Secular trend of colon cancer incidence and mortality in relation to fat and meat intake in Japan. Eur $J$ Cancer Prev, 13, 127-32.

Kono S, Toyomura K, Yin G, Nagano J, Mizoue T (2004). A case-control study of colorectal cancer in relation to lifestyle factors and genetic polymorphisms: Design and conduct of the Fukuoka Colorectal Cancer Study. Asian Pac J Cancer Prev, 5, 393-400.

Li C, Li Y, Gao LB, et al (2009). Vitamin D receptor gene 
Nobuyuki Takeshige et al

polymorphisms and the risk of colorectal cancer in a Chinese population. Dig Dis Sci, 54, 634-9.

Mahmoudi T, Karimi K, Mohebbi SR, et al (2011). Start codon FokI and intron $8 \mathrm{BsmI}$ variants in the vitamin D receptor gene and susceptibility to colorectal cancer. Mol Biol Rep, 38, 4765-70.

Mizoue T, Kimura Y, Toyomura K, et al (2008). Calcium, dairy foods, vitamin D, and colorectal cancer risk: The Fukuoka Colorectal Cancer Study. Cancer Epidemiol Biomarkers Prev, 17, 2800-7.

Morita M, Le Marchand L, Kono S, et al (2009). Genetic polymorphisms of CYP2E1 and risk of colorectal cancer: The Fukuoka Colorectal Cancer Study. Cancer Epidemiol Biomarkers Prev, 18, 235-41.

Morita M, Yin G, Yoshimitsu S, et al (2013). Folate-related nutrients, genetic polymorphisms, and colorectal cancer risk: the Fukuoka Colorectal Cancer Study. Asian Pac J Cancer Prev, 14, 6249-56.

Nassiri M, Kooshyar MM, Roudbar Z, Mahdavi M, Doosti M (2013). Genes and SNPs associated with non-hereditary and hereditary colorectal cancer. Asian Pac J Cancer Prev, 14, 5609-14.

Park K, Woo M, Nam J, Kim JC (2006). Start codon polymorphisms in the vitamin $\mathrm{D}$ receptor and colorectal cancer risk. Cancer Lett, 237, 199-206.

Peters U, Hayes RB, Chatterjee N, et al (2004). Circulating vitamin $\mathrm{D}$ metabolites, polymorphism in vitamin D receptor, and colorectal adenoma risk. Cancer Epidemiol Biomarkers Prev, 13, 546-52.

Raimondi S, Johansson H, Maisonneuve P, Gandini S (2009). Review and meta-analysis on vitamin D receptor polymorphisms and cancer risk. Carcinogenesis, 30, 117080.

Rasool S, Kadla SA, Khan T, et al (2013). Association of a VDR gene polymorphism with risk of colorectal cancer in Kashmir. Asian Pac J Cancer Prev, 14, 5833-7.

Slattery ML, Yakumo K, Hoffman M, Neuhausen S (2001). Variants of the VDR gene and risk of colon cancer (United States). Cancer Causes Control, 12, 359-64.

Slattery ML, Neuhausen SL, Hoffman M, et al (2004). Dietary calcium, vitamin D, VDR genotypes and colorectal cancer. Int J Cancer, 111, 750-6.

Theodoratou E, Farrington SM, Tenesa A, et al (2008). Modification of the inverse association between dietary vitamin D intake and colorectal cancer risk by a FokI variant supports a chemoprotective action of vitamin D intake mediated through VDR binding. Int J Cancer, 123, 2170-9.

Touvier M, Chan DS, Lau R, et al (2011): Meta-analyses of vitamin D intake, 25-hydroxyvitamin D status, vitamin D receptor polymorphisms, and colorectal cancer risk. Cancer Epidemiol Biomarkers Prev, 20, 1003-16.

Uchida K, Kimura Y, Shirota T, Kono S (2007). Validity and reproducibility of the PC-assisted dietary interview used in the Fukuoka Colorectal Cancer Study. Asian Pac J Cancer Prev, 8, 583-90.

Uitterlinden AG, Fang Y, Van Meurs JB, Pols HA, Van Leeuwen JP (2004). Genetics and biology of vitamin D receptor polymorphisms. Gene, 338, 143-56.

Willett WC (1990). Nutritional Epidemiology. Oxford University Press, Oxford.

Wong HL, Seow A, Arakawa K, et al (2003). Vitamin D receptor start codon polymorphism and colorectal cancer risk: Effect modification by dietary calcium and fat in Singapore Chinese. Carcinogenesis, 24, 1091-5.

World Cancer Research Fund and American Institute for Cancer Research (2007). Food, Nutrition, Physical Activity and the Prevention of Cancer: A Global Perspective. American
Institute for Cancer Research, Washington, DC.

Yamaji T, Iwasaki M, Sasazuki S, et al (2012). Association between plasma 25-hydroxyvitamin D and colorectal adenoma according to dietary calcium intake and vitamin D receptor polymorphism. Am J Epidemiol, 175, 236-44.

Yu K, Yang J, Hang Y, Song R, Lu Q (2014). Vitamin D receptor bsmi polymorphism and colorectal cancer risk: an updated analysis. Asian Pac J Cancer Prev, 15, 4801-7.

Zmuda JM, Cauley JA, Ferell RE (2000). Molecular epidemiology of vitamin D receptor gene variants. Epidemiol Rev, 22, 203-17. 